\title{
Pre-Ablation rhTSH-Stimulated F-18 FDG PET/CT Changes Patient Management in Increased-Risk Thyroid Cancer
}

\section{(두) (1) 요 $\ominus$}

Authors

Gundula Rendl, Lukas Rettenbacher, Gregor Schweighofer-Zwink, Lukas Hehenwarter, Christian Pirich

\section{Affiliation}

Department of Nuclear Medicine and Endocrinology, University

Hospital Salzburg, Paracelsus Medical University, Salzburg, Austria

Key words

F-18 FDG PET/CT, differentiated thyroid cancer, radioiodine ablation, recombinant human TSH, thyroglobulin, wholebody radioiodine scan, increased-risk thyroid cancer

$\begin{array}{ll}\text { received } & 09.04 .2019 \\ \text { accepted } & 23.01 .2020\end{array}$

Bibliography

DOI https://doi.org/10.1055/a-1111-8927

Horm Metab Res 2020; 52: 158-167

(c) Georg Thieme Verlag KG Stuttgart · New York

ISSN 0018-5043

Correspondence:

Gundula Rendl

Department of Nuclear Medicine and Endocrinology

University Hospital Salzburg, Paracelsus Medical University

Salzburg

Müllner Hauptstrasse 48

5020 Salzburg

Austria

Tel.: + 43 5/7255-26601, Fax: + 43 5/7255-26699

g.rendl@salk.at

Supplementary Material for this article is available online at http://www.thieme-connect.de/products.

\section{ABSTRACT}

The aim of the study was to evaluate the clinical impact of pre-ablation rhTSH-stimulated fluorine- 18 fluorodeoxyglucose (F-18 FDG) PET/CT in addition to post-therapeutic whole body radioiodine scanning in patients with intermediate to high risk differentiated thyroid carcinoma (DTC). This was a retrospective single center study including 73 patients with thyroid cancer (44 females, mean age $43.2 \pm 16.2$ years, $62 \%$ papillary, $31 \%$ follicular, $7 \%$ poorly differentiated). All patients underwent ablative radioiodine treatment (mean activity: $3661 \pm 673$ MBq I-131) using rhTSH after thyroidectomy and lymph node (LN) dissection (01/2013-10/2016) and TSH-stimulated F-18 FDG PET/CT (4 MBq/kg body weight, low dose CT). Post-treatment I-131 whole body scan (I-131 WBS) was obtained 9 days afterwards in planar technique and in case of equivocal or abnormal findings using SPECT/CT. Thirty-one patients (42\%) showed F-18 FDG avid lesions, 14 patients showed more FDG than iodine positive lesions and 5 patients more iodine positive lesions in I-131 WBS, respectively. Fifty-three patients showed identical F-18 FDG PET/CT and I-131 WBS. The initial treatment plan was changed from follow-up to therapy (surgery, systemic therapy using tyrosine-kinase inhibition) in 11 patients (15\%) on the basis of F-18 FDG PET/CT imaging. Six of these 11 patients had papillary thyroid cancer. Three patients with histologically proven LN metastases had stimulated thyroglobulin-levels $<2.0 \mathrm{ng} / \mathrm{ml}$. Our study demonstrated a clinical benefit of pre-ablation rhTSH-stimulated F-18 FDG PET/CT imaging in about $20 \%$ of patients with intermediate to high risk DTC, leading to change in patient management in $15 \%$.

\section{Introduction}

Thyroid cancer is the most common endocrine malignancy. Its incidence continues to rise annually worldwide, with 762 new cases per 100000 per year in 2015 in Austria [1]. Differentiated thyroid carcinoma (DTC), which includes papillary and follicular histological types, account for the vast majority (>90\%) of all thyroid cancer cases [2].

Primarily, surgical removal of the thyroid followed by radioactive iodine therapy (RIT) is the standard of care for DTC in Austria. RIT is used to decrease the incidence of recurrent disease and to ablate all thyroid remnant tissue following thyroidectomy [3]. The result of the post-treatment whole-body radioiodine scan (I-131 WBS) provides information about most commonly observed lymph node metastases and distant metastases ( $\mathrm{N}$ - and M-stage) [4].

Fluorine-18 fluorodeoxyglucose (F-18 FDG) positron emission tomography/computed tomography (PET/CT) is widely used in the diagnosis, staging, and surveillance of several malignancies. For DTC, the use of F-18 FDG scans has been primarily established to postoperative surveillance in high-risk patients with distant metastases, elevated or rising serum thyroglobulin (TG) levels and negative I-131 WBS in the follow up [5-8]. 
After initial treatment, thyroid carcinoma recurrences occurred in $10-15 \%$ of cases especially in patients with an aggressive histological type or extensive local disease [9]. Approximately two thirds of patients with metastatic disease exhibited radioiodine avid lesions, while the remaining were classified as "radioiodine-refractory disease" based on a negative I-131 WBS but with evidence of tumor lesion on CT scans and elevated thyroglobulin levels [9]. According to Schlumberger et al. [10] patients with radioiodine-refractory DTC are divided into four categories: 1) patients with metastatic disease that does not show radioiodine uptake at the time of initial treatment; 2 ) patients whose tumors lose the ability to take up radioiodine after previous evidence of radioiodine uptake; 3) patients with radioiodine uptake in some lesions but not in others; and 4) patients with metastatic disease that progresses despite substantial radioiodine uptake.

F-18 FDG PET/CT is useful to identify additional clinically relevant metastatic tissue in radioiodine-refractory patients that might require additional localized intervention such as surgery, external beam radiation therapy among others, as well as to help to determine the progression and the response to targeted molecular therapies [7, 11-13].

In our retrospective study, we aimed to evaluate the added value of pre-ablation rhTSH-stimulated F-18 FDG PET/CT in comparison to the post-therapeutic whole body radioiodine scan in patients with advanced thyroid carcinoma and to characterize the proportion of patient with radioiodine refractory state after initial radioiodine therapy.

\section{Materials and Methods}

\section{Patients}

This retrospective study included 73 patients with intermediate-to-high-risk histologically proven differentiated thyroid carcinoma who underwent both FDG PET/CT and initial I-131 ablation in the Department of Nuclear Medicine and Endocrinology, Paracelsus Medical University Salzburg, Austria from January 2013 to October 2016.

The department is the only institution providing RIT therapy for a population of approximately 550000 inhabitants in the federal republic of Salzburg. In our institution, FDG PET/CT imaging has been defined as standard of care in $\mathrm{T} 2$ tumors with histologically confirmed LN metastases at the time of surgery and T3 and T4 tumors irrespective of lymph node status (UICC TNM 7). The study protocol defined the presence of above given tumors as inclusion criteria. Patients with anaplastic or medullary thyroid cancer were excluded from analysis.

Among 73 sequential patients, 44 were females and 29 were males, with a mean age of $43.2 \pm 16.2$ years. Histology revealed papillary thyroid cancer in 45 patients (62\%, follicular variant in 10 patients), follicular thyroid cancer in 23 patients (31\%, oxyphilic variant in 5 patients), and poorly differentiated thyroid cancer in 5 patients ( $7 \%$ ), respectively. T2 tumors were found in 4 patients ( 1 multifocal), T3 tumors in 61 patients ( 14 multifocal), T4 tumors in 7 patients ( 6 patients $\mathrm{PT} 4,1$ patient cT4), and PTxNOM 1 in one patient, respectively.
The study was part of a thyroid cancer project approved by an institutional review board and in accordance with the ethical standards of the Helsinki declaration. All procedures performed in this study were part clinical routine SOPs, Written informed consent was obtained from all individual participants included in this study.

\section{I-131 ablation}

All patients underwent initial ablation in the Department of Nuclear Medicine and Endocrinology, Paracelsus Medical University Salzburg, Austria after total or near-total thyroidectomy. Patients were instructed to follow a low-iodine diet for 2 weeks prior of the ablation RAI. Recombinant human thyroid stimulating hormone (rhTSH) was administered to all patients over two consecutive days (0.9 mg rhTSH - Thyrogen ${ }^{\circledR}$, Genzyme Europe B.V., Naarden, Netherlands - per day). A mean dose of $3661 \pm 673 \mathrm{MBq}$ l-131 (median 3617, range 1757-5956) was administered [Supplementary Material - $>$ Table 1S]. Post-treatment whole body scans were obtained 9 days after therapy in planar and SPECT/CT technique using a large field of view gamma camera (Symbia T6 or E-CAM; Siemens Medical Solutions, Erlangen, Germany) on a photo peak of $364 \mathrm{keV}$ with a high-energy collimator.

SPECT/CT was performed on demand using the Symbia T6 (Siemens Medical Solutions, Erlangen, Germany) with 36 views á $45 \mathrm{~s}$ and Flash 3D ( 8 iterations, 4 subsets) for reconstruction. A low-dose CT (effective $30 \mathrm{mAs}$ dose-modulated, $130 \mathrm{kV}$ ) was performed for anatomical correlation.

\section{F-18 FDG PET/CT}

All patients underwent F-18 FDG PET/CT with low dose CT on the day of I-131 ablation after rhTSH-stimulation. Patients were required to fast for at least $6 \mathrm{~h}$ prior to PET/CT imaging. PET images were acquired 60 min after injection of an intended activity of 4 $\mathrm{MBq} / \mathrm{kg}$ F-18 FDG (mean activity $310 \pm 59 \mathrm{MBq}$ F-18 FDG). Scans were acquired from the apex of the skull to the mid-thighs in 3-D mode, $7-10$ beds, 75 s per bed position. Prior to PET acquisition, a low dose $\mathrm{CT}$ acquisition for attenuation correction and anatomical correlation was performed with the same longitudinal field of view. PET images were reconstructed on a $144 \times 144$ matrix, using an iterative algorithm (BLOB-OS-TF). CT images were reconstructed on a $512 \times 512$ matrix using the usual Filtered Back Projection algorithm. After reconstruction, the final slice thickness was 4 and $3 \mathrm{~mm}$ regarding $\mathrm{PET}$ and $\mathrm{CT}$, respectively.

\section{Image interpretation}

Board-certified experienced nuclear medicine physicians interpreted all F-18 FDG PET/CT scans and I-131 WBS. The uptake of F-18 FDG and I-131 was evaluated in the thyroid bed, lymph nodes (cervical and mediastinal lymph nodes) and distant metastases (bone, lung, among others).

\section{Thyroglobulin measurement}

Serum thyroglobulin (TG) was measured (Elecsys TG II Cobas, Roche Diagnostics $\mathrm{GmbH}$, Mannheim, Germany) on the treatment day following two days of TSH stimulation using rhTSH. 


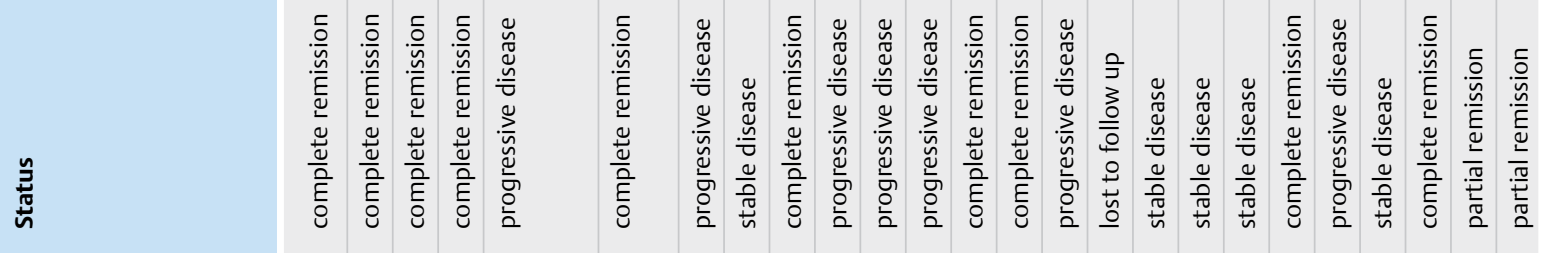

苞
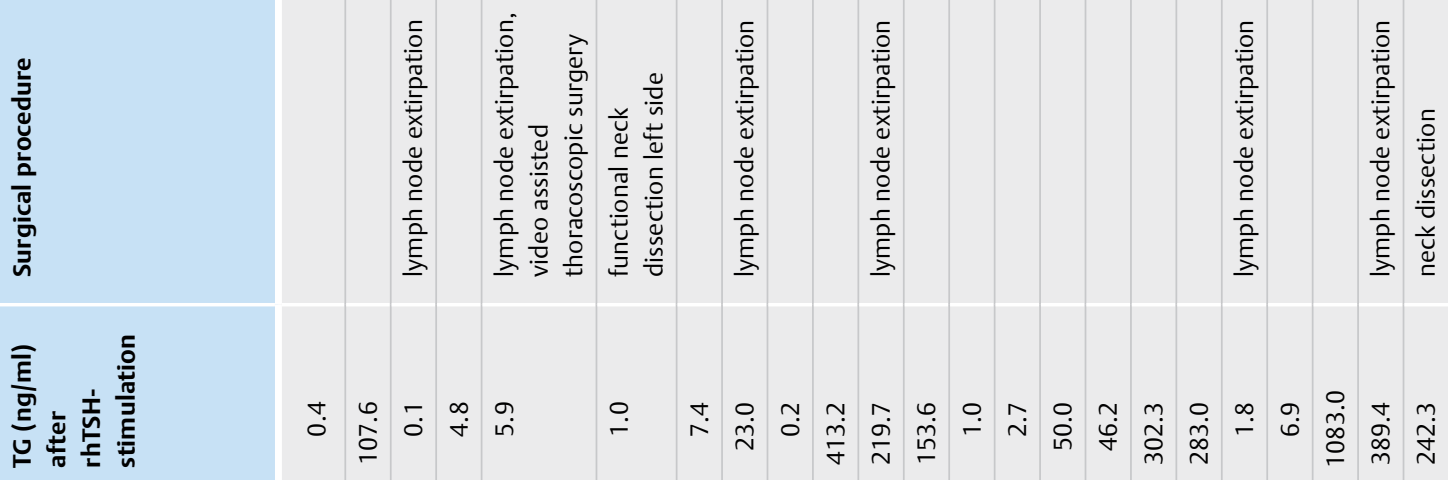

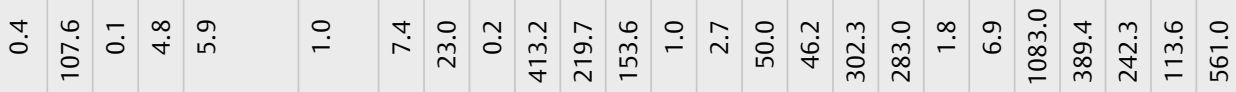

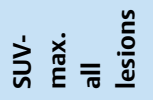

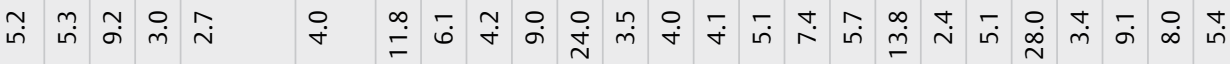

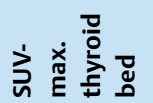

\begin{tabular}{ll|lll}
$\stackrel{m}{*}$ & $\stackrel{m}{i}$ & $\stackrel{+}{N}$ & $\stackrel{+}{*}$
\end{tabular}

$\stackrel{\sim}{\stackrel{+}{*}} \stackrel{\circ}{\circ}$

テ

$\stackrel{\circ}{\dot{m}} \stackrel{\infty}{m}$

\begin{tabular}{l|l|l}
$\stackrel{\nabla}{r}$ & $\stackrel{\nabla}{m}$ & $\stackrel{+}{*}$
\end{tabular}

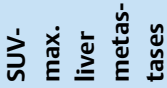

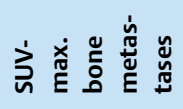

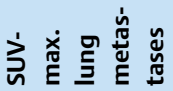

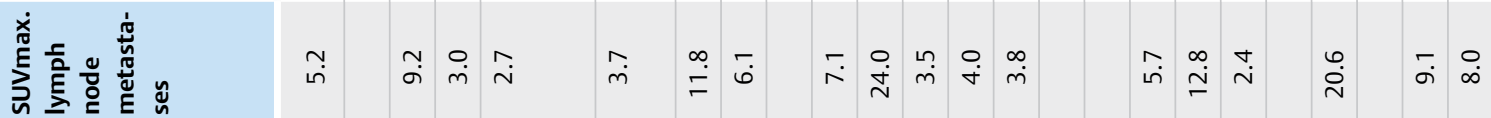

긍

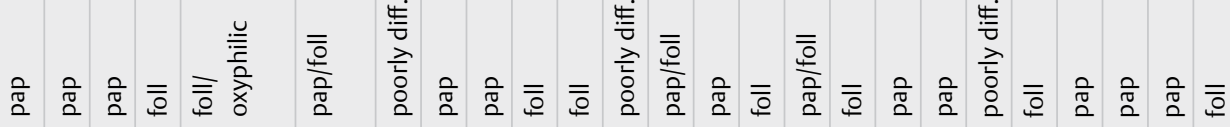

营

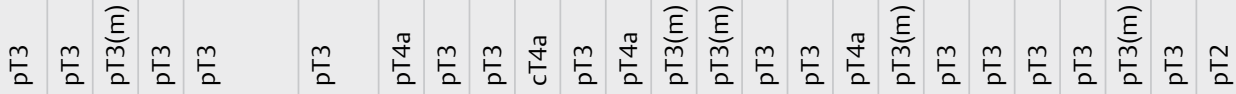

๖ั

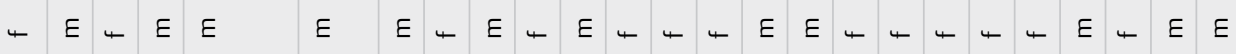

gั

ㅂำ

$\stackrel{\dot{E}}{\dot{\pi}}$

N

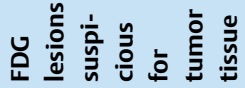




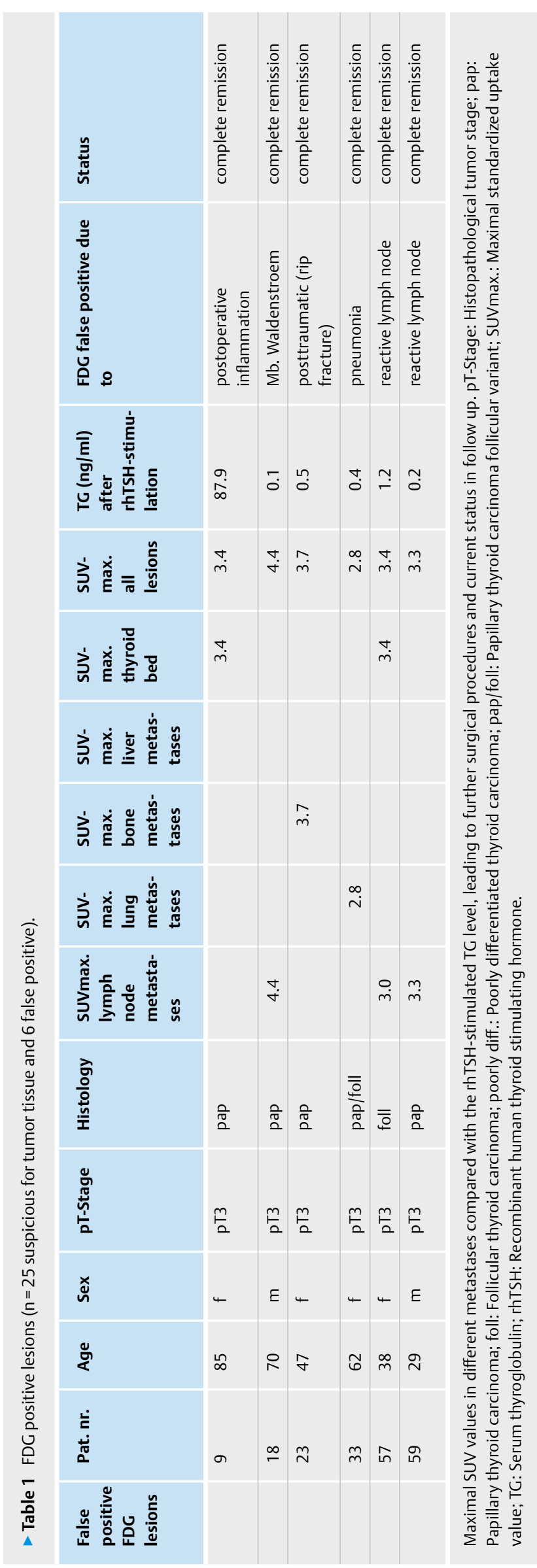

\section{Results}

\section{F-18 FDG PET/CT}

Thirty-one out of 73 patients ( $42 \%$ ) showed a pathological uptake in F-18 FDG PET/CT imaging. Of these 31 patients with positive F-18 FDG PET/CT imaging, the uptake in 25 patients (81\%) was interpreted as positive for tumor tissue or thyroid remnant and 6 patients (19\%, patient nr. $9,18,23,33,57$, and 59) as false positive due to unspecific (inflammatory) uptake ( $\triangleright$ Table 1 ).

Fourteen out of 31 patients ( $45 \%$ ) showed more F-18 PET/CT positive lesions than lesions found in the I-131 WBS ( $\triangleright$ Fig. 1), 13 patients (42\%) showed identical uptake in PET/CT and I-131 WBS, and the remaining 4 patients (13\%) showed more lesions in the I-131 WBS than in the PET scan ( $>$ Fig. 2), respectively ( $>$ Table 1 ). F-18 FDG uptake regions suspicious for tumor tissue included the thyroid bed ( $n=15$ patients), cervical lymph nodes ( $n=13$ patients), mediastinal lymph nodes ( $n=8$ patients) and axillary lymph nodes ( $n=1$ patient). Twenty-one of 31 patients (68 \%) showed F-18 FDG accumulation beyond the thyroid bed. Distant metastases could be seen in 7 patients. Lung metastases were observed in 6 patients, bone metastases in 4 patients, and hepatic metastasis in one patient, respectively ( $\vee$ Table $\mathbf{1})$.

TG levels on the treatment day were higher in PET-positive patients (median $=48.1 \mathrm{ng} / \mathrm{ml}$ ) than in those who were PET-negative ( median $=1.0 \mathrm{ng} / \mathrm{ml})$.

The median SUVmax was 4.4 in all FDG-avid lesions (range 2.428.0; mean 6.6 \pm 5.6 ). Tumor-lesions confirmed by histology exhibited a median SUVmax of 5.1 (range 2.4-24,0; mean 7.6 \pm 7.1 ) while lesions with inflammatory/unspecific uptake had a median SUVmax of 3.4 (range 2.8-4.4; mean $3.5 \pm 0.5$ ).

\section{Comparison of F-18 FDG PET/CT and I-131 WBS}

Fourteen patients out of 73 (20\%) showed more lesions in F-18 FDG PET/CT scan than in I-131 WBS (13 patients showed iodine uptake only in the thyroid bed and not in lymph nodes or organs, and the last patient showed no iodine uptake in a PET positive bone metastasis).

In 53 patients (73\%) F-18 FDG PET/CT imaging corresponded with the I-131 WBS result and in five patients (7\%) I-131 WBS revealed more iodine positive lesions than F-18 FDG positive ones ( Table 2).

The treatment plan was changed from follow-up to additional surgery due to initial FDG PET/CT or iodine scan in 9 patients (histologically verified lymph node metastases $n=24$ and one supraclavicular soft tissue metastasis - patient nr. 11, 21, 30, 31, 34, 42, 62,69 , and 70), while 2 patients underwent tyrosinkinase-inhibition therapy (patient nr. 40 and 64). One of the nine patient refused to undergo further surgery and progressed clinically in follow up (patient nr. 32 with wide tumor infiltration into the hypopharynx on the right side with an $6 \mathrm{~cm}$ tumor in craniocaudal diameter).

Three patients with histologically proven metastases had very low TG levels ( $<5 \mathrm{ng} / \mathrm{ml}$ ), whereas the others had higher TG levels postoperatively ( $\vee$ Table 3 ).

\section{TG levels after stimulation}

The median TG level on treatment day following two days of TSH stimulation using rhTSH was $2.0 \mathrm{ng} / \mathrm{ml}$ (range 0.1 to $1145.0 \mathrm{ng} / \mathrm{ml}$; 


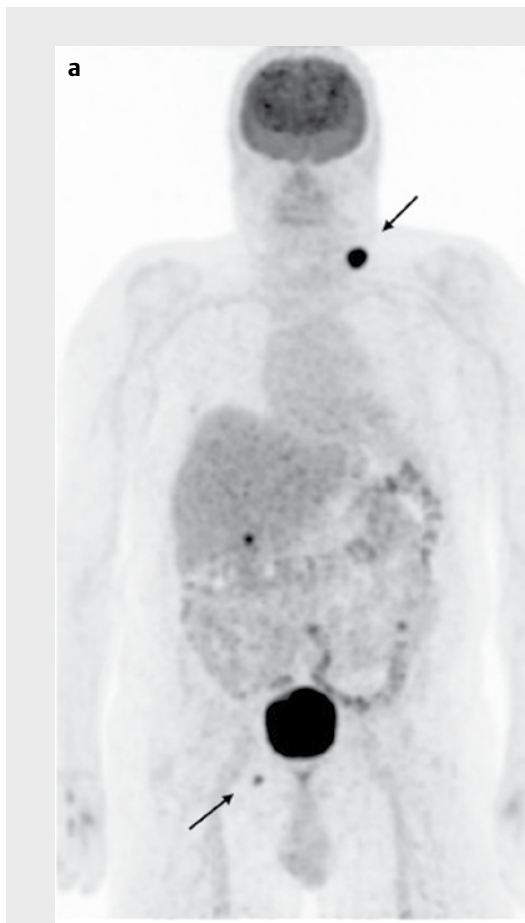

F-18 FDG PET/CT MIP
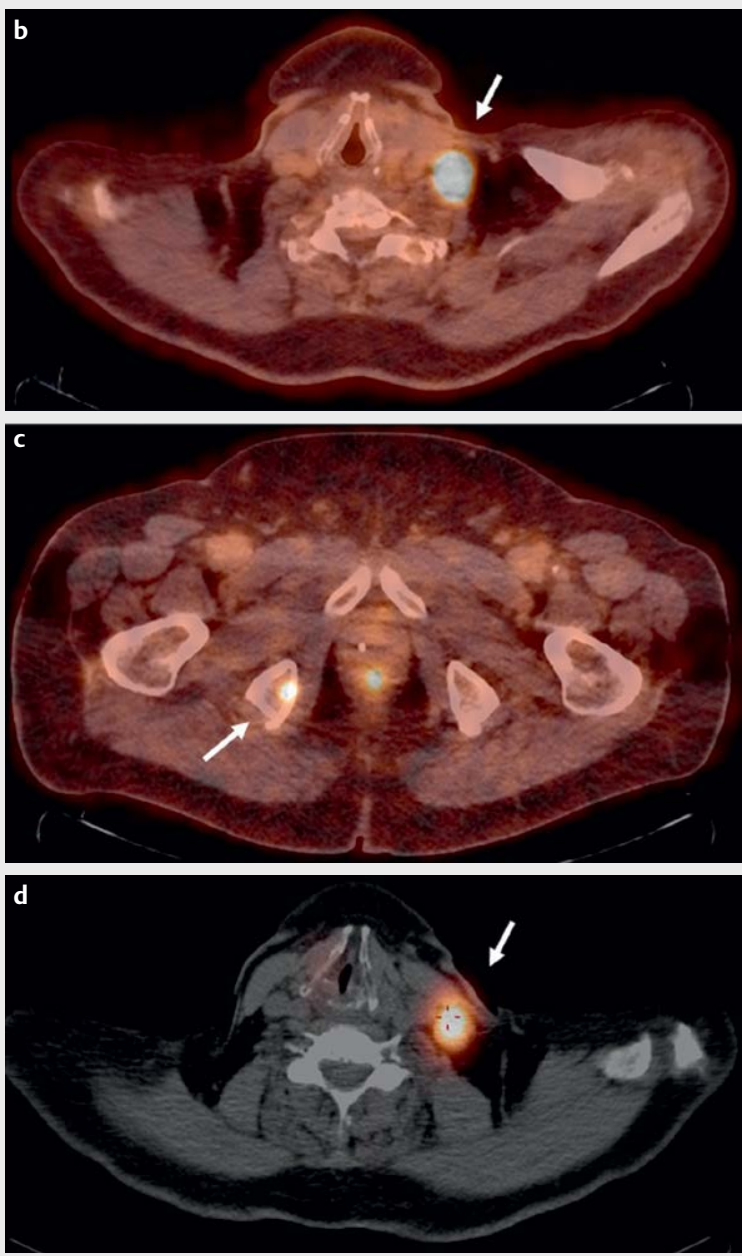

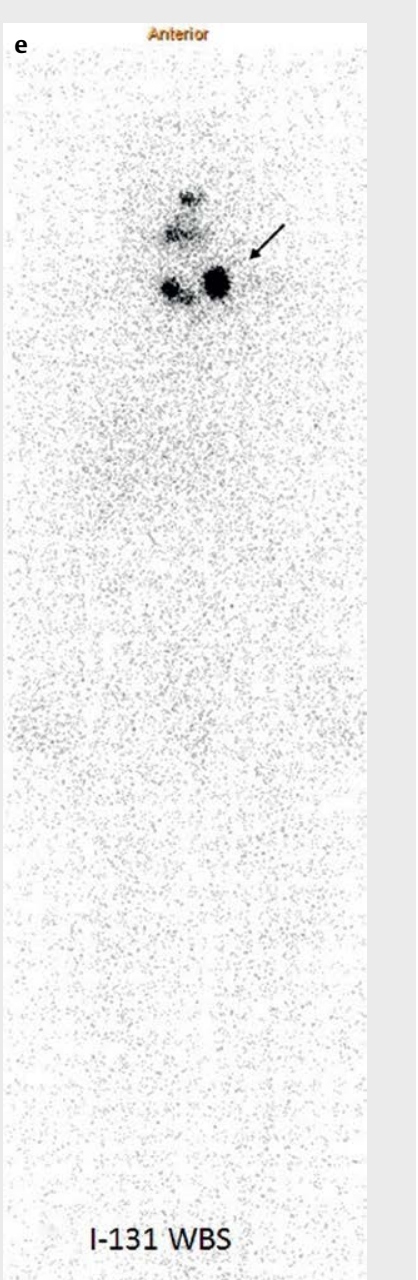

- Fig. 1 Patient no. 42: 73 year-old male patient, follicular thyroid cancer, pT3 N1b M1 with FDG and iodine positive lymph node metastasis und FDG positive and iodine negative bone metastasis 1a-c F-18 FDG PET/CT; MIP: Moving image projection; 1 b supraclavicular lymph node metastasis left side; 1c bone metastasis right os ischia; 1d,e I-131 WBS (WBS: Whole body scan); 1d I-131 SPECT/CT: Supraclavicular lymph node metastasis left side.

mean $75.6 \pm 205.9 \mathrm{pg} / \mathrm{ml}$ ). Forty-three patients had TG levels $<4 \mathrm{ng} /$ $\mathrm{ml}$ postoperatively and the remaining 30 patients $>4 \mathrm{ng} / \mathrm{ml}$. Twelve patients showed TG levels $>100 \mathrm{ng} / \mathrm{ml}, 11$ of them had pathologic FDG PET/CT scans (only patient nr. 53 showed no FDG uptake, but multiple iodine positive bilateral lung metastases). Three patients with histologically proven metastases ( $\triangleright$ Table 3 ) had postoperatively low stimulated TG levels $(<2.0 \mathrm{ng} / \mathrm{ml})$ and underwent second surgery indicated by F-18 FDG PET/CT findings, only.

\section{Follow up}

During follow up nine patients showed progressive disease: Patient nr. 1 with F-18 FDG PET/CT positive pulmonary metastasis, soft tissue metastases and mediastinal lymph node metastases on follow-up (surgery and histological verification), nr. 5 with progressive metastatic disease in multiple bone metastases and stable hepatic lesions under lenvatinib (Lenvima ${ }^{\circledR}$, Eisai Europe Ltd., Hatfield, UK) and local radiation therapy, nr. 21 with iodine positive bilater- al soft tissue metastases cervically and lymph node metastases in the mediastinum as well as a stable iodine negative pulmonary metastasis.

Patient nr. 32 (ineligible for surgery), nr. 40 - tumor progression with disseminated bilateral lung metastases, multiple lymph node metastases and osseous metastases, as well as two hepatic metastases - under sorafenib (Nexavar ${ }^{\circledR}$, Bayer AG, Leverkusen, Germany), then switch to lenvatinib and local palliative radiation therapy, patient nr. 42 with new lymph node metastases left cervical region, as well as a lung metastasis in the right upper lobe and a new bone metastasis in the sternum. Patient nr. 43 with new lymph node metastases in the jugulum, and pat. nr. 49 with lymph node metastases paratracheal in the jugulum and supraclavicular on the left side, and last patient $\mathrm{nr}$. 64 with new osseous metastases in the right frontal lobe, the right humerus and L1, as well as stable metastases in local lymph nodes, liver and lung under lenvatinib therapy. 


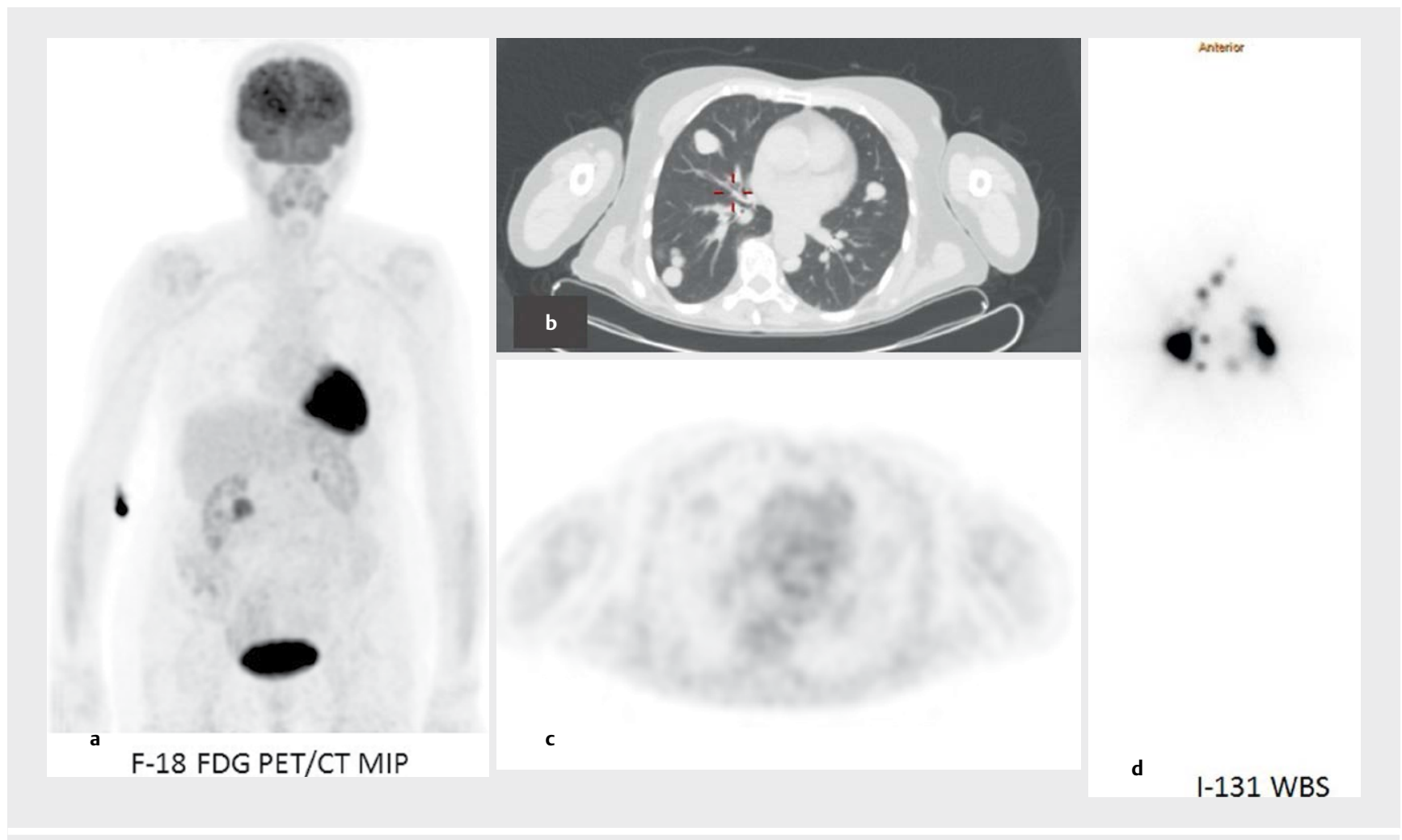

- Fig. 2 Patient no. 53: 75 year old female patient, follicular thyroid cancer, PTx N0 M1 with functional pulmonary metastases - FDG negative and iodine positive 2a-c F-18 FDG PET/CT; MIP: Moving image projection; 2b CT only - pulmonary metastases; 2c PET only - FDG negative pulmonary metastases; 2 d I-131 WBS (WBS: Whole body scan); iodine positive pulmonary metastases.

Seven out of 9 patients with progressive disease had initially pathologic F-18 FDG uptake and 4 patients showed no pathologic iodine uptake in the initial RIT (3 patients only uptake in thyroid bed, one patient no iodine uptake at all). Two patients showed no pathological F-18 FDG uptake and only iodine uptake in the thyroid bed in the initial RIT, however, patient nr. 1 (papillary thyroid carcinoma, pT3) developed metastases in lymph nodes, lung and soft tissue 27 months after surgery, and patient nr. 5 (follicular thyroid carcinoma, pT3) developed multiple bone metastases and hepatal metastases 23 months after surgery.

Five patients had a partial remission and 8 patients a stable disease during follow up ( 7 with pathologic F-18 FDG uptake and 5 patients with extrathyreoidal iodine uptake in RIT), 44 patients had no relapse, and the remaining 7 patients were lost to follow up.

\section{Discussion}

Our study confirms previous studies showing that rhTSH-stimulated F-18 FDG PET/CT imaging identified a substantial proportion of patients with locoregional and distant metastases but iodine-negative lesions in post-therapeutic scanning [14-17]. A clinically significant proportion of intermediate- and high-risk patients (14 out of 73, 20\%) exhibited unknown metastatic lesions in F-18 FDG PET/ CT compared to I-131 WBS. This information changed the treatment plan in 11 patients (15\%) from follow-up to further treatment, most commonly lymph node surgery, but also the use of local radiation therapy or systemic treatment by the use of tyrosine-kinase inhibitors. Four out of these 11 patients had a negative RIT and histologically proven thyroid metastases. In contrast, Leboulleux et al. [14] reported a change in treatment plan in merely $6 \%$ in a multicenter study with 63 patients.

Notably, our study identified F-18 FDG PET-positive lesions also in DTC patients with low postoperative stimulated TG levels before radioiodine ablation, which is in contrast to the study of Leboulleux et al. restricting F-18 FDG PET/CT imaging to patients with TG levels $>10 \mathrm{ng} / \mathrm{ml}$ [14]. The positive relation between the level of TSH-stimulated TG and the sensitivity and accuracy of F-18 FDG $\mathrm{PET} / \mathrm{CT}$ scans in the presence of a negative iodine scans is widely documented [15-17]. Thus, a cut-off TG-level of $5 \mathrm{ng} / \mathrm{ml}$ or higher has been recommended for initiating F-18 FDG PET/CT imaging in follow up of DTC $[14,17]$.

The value of FDG PET/CT imaging in the detection of RAI-negative tumor lesions in the presence of low TG levels might be attributed to particular histologic subtypes, that is, oxyphilic variant. It has been shown that F-18 FDG PET/CT imaging is more sensitive in patients with an aggressive histological tumor subtype, such as poorly differentiated, Hürthle cell or tall cell thyroid carcinoma $[18,19]$.

Astonishingly, our study also demonstrated an impact of F-18 FDG PET/CT imaging in well-differentiated thyroid cancer types, since 14 out of 26 FDG-positive patients had a papillary form. Impaired radioiodine uptake might be also present in DTC either due 


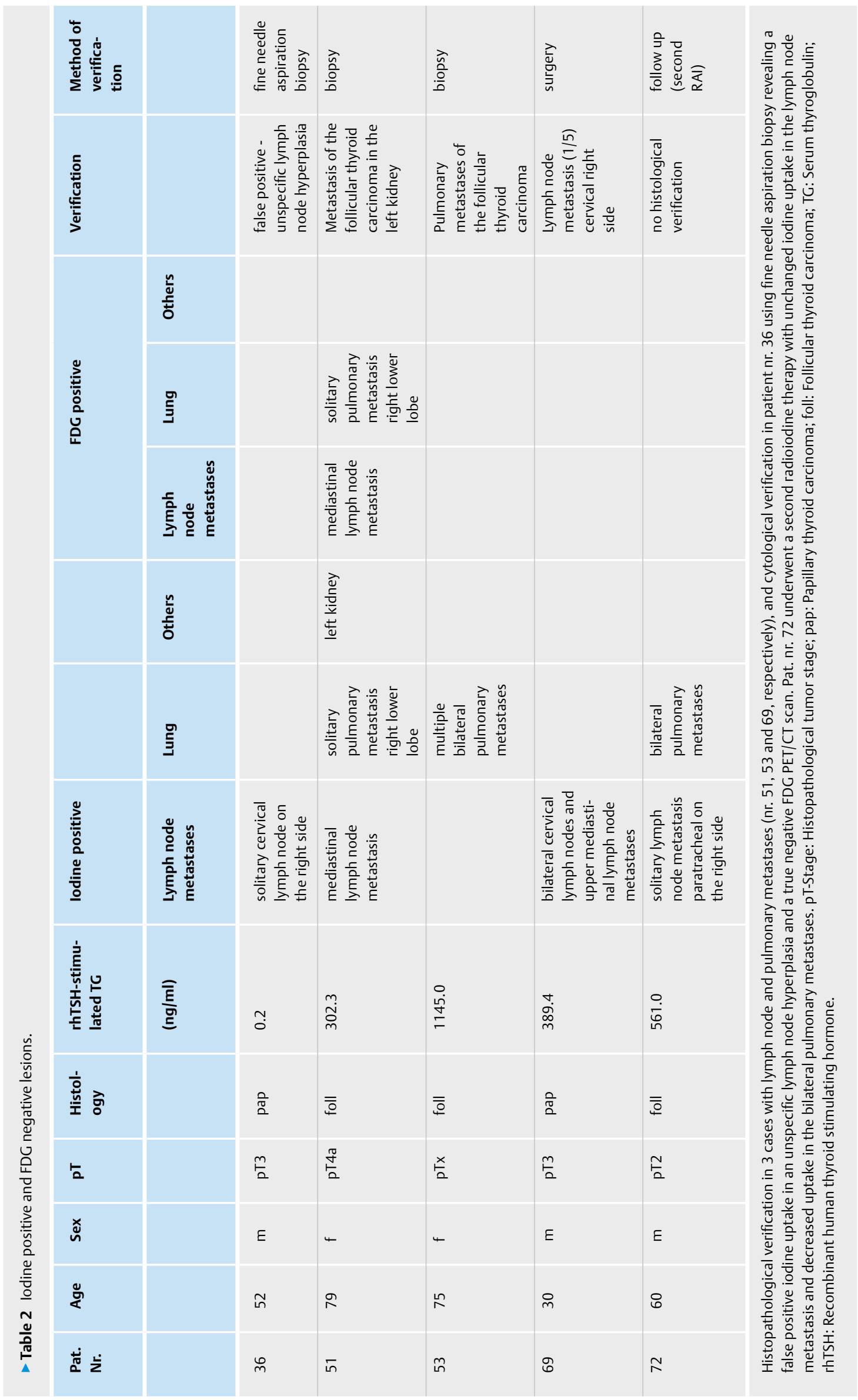


- Table 3 Histologically proven metastases in comparison to the uptake in the iodine scan and the FDG PET/CT as well as stimulated thyroglobulin levels.

\begin{tabular}{|c|c|c|c|c|c|c|c|c|c|c|c|}
\hline $\begin{array}{l}\text { Pat. } \\
\text { nr. }\end{array}$ & Age & Sex & pT & Histology & RAI & PET positive & $\begin{array}{l}\text { SUV- } \\
\max \end{array}$ & $\begin{array}{l}\text { TG (ng/ } \\
\text { ml) after } \\
\text { rhTSH }\end{array}$ & $\begin{array}{l}\text { TAK } \\
(<4.11 \\
\text { IU/ml) }\end{array}$ & Histology & Status \\
\hline 11 & 32 & $f$ & $\mathrm{pT} 3(\mathrm{~m})$ & pap & $\begin{array}{l}\text { discretly in } \\
\text { jugulum }\end{array}$ & $\begin{array}{l}\text { jugulum and } \\
\text { lymph node left } \\
\text { cervical region }\end{array}$ & 9.2 & 0.1 & 67.68 & $\begin{array}{l}2 \text { lymph node } \\
\text { metastases }\end{array}$ & $\begin{array}{l}\text { complete } \\
\text { remission }\end{array}$ \\
\hline 21 & 77 & $\mathrm{~m}$ & pT3 & oxyphilic & $\begin{array}{l}\text { thyroid bed } \\
\text { right side }\end{array}$ & $\begin{array}{l}\text { lymph nodes on } \\
\text { cervical left and } \\
\text { mediastinum, } \\
\text { right thyroid bed }\end{array}$ & 2.7 & 5.9 & & $\begin{array}{l}2 \text { lymph node } \\
\text { metastases } \\
\text { (paraaortal } \\
\text { und retroclav- } \\
\text { icular) }\end{array}$ & $\begin{array}{l}\text { progressive } \\
\text { disease }\end{array}$ \\
\hline 30 & 49 & $\mathrm{~m}$ & pT3 & pap/foll & $\begin{array}{l}\text { thyroid bed } \\
\text { right side }\end{array}$ & $\begin{array}{l}\text { Cervical lymph } \\
\text { node }\end{array}$ & 4.0 & 1.0 & 1.41 & $\begin{array}{l}\text { solitary lymph } \\
\text { node } \\
\text { metastasis left } \\
\text { cervical }\end{array}$ & $\begin{array}{l}\text { complete } \\
\text { remission }\end{array}$ \\
\hline 34 & 66 & $f$ & pT3 & pap & $\begin{array}{l}\text { thyroid bed } \\
\text { left side }\end{array}$ & $\begin{array}{l}\text { Cervical lymph } \\
\text { nodes in jugulum } \\
\text { and paratracheal } \\
\text { right side }\end{array}$ & 6.1 & 23.0 & 0.61 & $\begin{array}{l}4 \text { lymph node } \\
\text { metastases } \\
\text { infrajugular } \\
\text { and one right } \\
\text { paratracheal }\end{array}$ & $\begin{array}{l}\text { stable } \\
\text { disease }\end{array}$ \\
\hline 42 & 72 & $\mathrm{~m}$ & pT3 & foll & $\begin{array}{l}\text { cervical } \\
\text { lymph node } \\
\text { on the left } \\
\text { side, } \\
\text { thyroid bed }\end{array}$ & $\begin{array}{l}\text { cervical lymph } \\
\text { node on the left } \\
\text { side and solitary } \\
\text { bone metastasis } \\
\text { in os ischii on the } \\
\text { right side }\end{array}$ & 24.0 & 219.7 & 1.51 & $\begin{array}{l}\text { soft tissue } \\
\text { metastasis } \\
\text { supraclavicular } \\
\text { left side }\end{array}$ & $\begin{array}{l}\text { progressive } \\
\text { disease }\end{array}$ \\
\hline 62 & 32 & $f$ & pT3 & pap & $\begin{array}{l}\text { thyroid bed } \\
\text { right side }\end{array}$ & $\begin{array}{l}\text { cervical lymph } \\
\text { node left side }\end{array}$ & 2.4 & 1.8 & & $\begin{array}{l}\text { solitary lymph } \\
\text { node } \\
\text { metastasis }\end{array}$ & $\begin{array}{l}\text { stable } \\
\text { disease }\end{array}$ \\
\hline 69 & 30 & $\mathrm{~m}$ & pT3 & pap & $\begin{array}{l}\text { bilateral } \\
\text { cervical } \\
\text { lymph } \\
\text { nodes }\end{array}$ & $\begin{array}{l}\text { cervical lymph } \\
\text { node right side }\end{array}$ & 3.4 & 389.4 & 0.92 & $\begin{array}{l}\text { solitary lymph } \\
\text { node } \\
\text { metastasis } \\
\text { right cervical }\end{array}$ & $\begin{array}{l}\text { stable } \\
\text { disease }\end{array}$ \\
\hline 70 & 36 & $f$ & $\mathrm{p} T 3(\mathrm{~m})$ & pap & $\begin{array}{l}\text { thyroid bed } \\
\text { right side }\end{array}$ & $\begin{array}{l}\text { cervical lymph } \\
\text { nodes right side }\end{array}$ & 9.1 & 242.3 & & $\begin{array}{l}12 \text { lymph node } \\
\text { metastases }\end{array}$ & $\begin{array}{l}\text { complete } \\
\text { remission }\end{array}$ \\
\hline
\end{tabular}

pT-Stage: Histopathological tumor stage; pap: Papillary thyroid carcinoma; foll: Follicular thyroid carcinoma; pap/foll: Papillary thyroid carcinoma follicular variant; RAl: Radioactive iodine scan; TG: Serum thyroglobulin; rhTSH: Recombinant human thyroid stimulating; TAK: Thyroglobulin antibodies.

to absent or decreased expression of the sodium iodine symporter gene [20] or due to inadequate targeting of the cell membrane [21].

Post-translational downregulation of membranous $\mathrm{Na}^{+} / \mathrm{I}^{-}$symporter (NIS) expression has been recently described [22]. Furthermore, the correlation between the predictability of radioiodine uptake by metastases based on NIS expression in the primary tumor is controversial [23-25]. These findings support the use of F-18 FDG $\mathrm{PET} / \mathrm{CT}$ imaging to obtain clinical useful information about tumor stage and biological behavior.

In patients with known metastatic disease, F-18 FDG PET/CT indicates radioiodine-refractory disease, but may also reveal a mixed FDG/iodine uptake in metastases. Any FDG uptake in metastases indicates a more aggressive disease and RIT treatment is less effec- tive in these patients $[10,12,26-28]$. Advanced radioiodine-refractory disease occurs more frequently in older patients, in patients with large metastases, in those with FDG positive lesions and therefore a more aggressive tumor behavior, as well as in poorly differentiated thyroid cancer [12, 27-29].

In our patient cohort, no significant age difference could be seen with respect to FDG-avidity (mean age of $58.6 \pm 17.8$ years in PET positive patients and $60.5 \pm 14.6$ years in PET negative patients, respectively). The patients with poorly differentiated thyroid cancer were PET positive $(n=3)$ and PET negative $(n=2)$, respectively. T-Stage was also balanced in the two groups: $\mathrm{pT} 2=3, \mathrm{pT} 3=34$, pT4 $=4$ and $\mathrm{pTx}=1$ in PET negative patients and $\mathrm{pT} 2=1, \mathrm{pT} 3=26$ and $\mathrm{pT} 4=4$ in the PET positive patients, respectively.( $\triangleright$ Table 1S) 
It is a feature of our study that all F-18 FDG PET/CT studies were performed after rhTSH stimulation, increasing its lesion-based sensitivity as postulated by Leboulleux et al. [14]. In this prospective, multicenter study on 63 patients, an increase in the number of detected lesions after rhTSH stimulation in F-18 FDG PET/CT compared to a basal F-18 FDG PET/CT performed on (TSH-suppressive) thyroid hormone treatment could be found. However, the use of rhTSH stimulated F-18 FDG PET/CT only increased significantly the number of lesions detected, but not the number of patients with FDG-avid lesions itself. However, the number and distribution of lesions surely influence the clinical decision concerning further treatment planning. Additionally, false positive lesions occur with or without TSH stimulation in F-18 FDG PET/CT-imaging to the same degree [14].

F-18 FDG PET/CT imaging may display false-positive lesions in up to $39 \%$ of patients $[12,14]$. Agate et al. [30] evaluated different imaging techniques for detection of metastases in DTC patients with negative post-therapeutic iodine whole-body scan and detectable serum TG levels and concluded that neck ultrasound is better than F-18 FDG PET in the detection of lymph node metastases due to both false positive and negative results in F-18 FDG PET. Therefore fine needle aspiration biopsy (FNAB) and cytology and/ or TG measurement within the aspirate fluid should be applied in patients in which re-surgery is recommended based on F-18 FDG PET/CT imaging.

The interval to initial surgery might also influence the rate of FDG-positive lymph nodes, as early imaging after surgery might cause an increased unspecific uptake related to inflammation. We had a mean interval of 4 weeks between surgery and F-18 FDG PET/ CT imaging, making this less likely.

In our patient cohort, we verified lymph node metastases pre-surgically using FNAB in two patients with F-18 FDG PET/CT positive lymph node metastases. However, we also encountered a false-positive iodine uptake in a cervical lymph node (FDG negative) using FNAB. Our study is in accordance with previous studies emphasizing the prognostic value of F-18 FDG PET/CT in intermediate and high-risk thyroid cancer. Seven out of 9 patients with progressive disease exhibited already an initially positive F-18 FDG PET/ CT scan.

In a study of Durante et al. [29], patients with radioiodine-refractory disease had a poor prognosis compared to non-radioiodine-refractory patients and a median life expectancy of 3-6 years. F-18 FDG PET/CT can help select patients for other treatment modalities, such as surgery, local radiation therapy or multikinase inhibitors [31,32].

A limitation of this study is its retrospective nature. A selection bias is unlikely due to the fact that patient selection was mainly based on baseline tumor size. Just four patients with $\mathrm{T} 2$ underwent F-18 FDG PET/CT imaging. Thus, study results do not relate to the majority of patients compromising of T1 and T2 tumors [33]. Another limitation of this study is that not all F-18 FDG PET positive lesions could be histologically confirmed. This was not feasible in patients with distant metastases to the bone or the lung, since a surgical strategy is inappropriate in the absence of complications, for example, risk of fracture. The gold standard, histological verification was obtained in eight patients (all with lymph node metas- tases). In further follow up, nine patients showed progressive disease; however, since patients were enrolled from January 2013 to October 2016, the adequate observation time for possible progression may be yet too short in some patients.

\section{Conclusion}

About $20 \%$ of patients with intermediate- or high risk DTC had rhTSH-stimulated FDG PET/CT positive but radioiodine-negative metastases upon initial treatment. This led to a change in patient management in 11 patients (15\%). We suggest further studies and longer observation periods to evaluate whether the use of FDG PET/ CT imaging just before RAl is of clinical benefit concerning outcome (PFS, OS) in intermediate and high-risk DTC irrespectively of stimulated TG levels.

\section{Conflict of Interest}

The authors declare that they have no conflict of interest.

\section{References}

[1] Statistik Austria, Österreichisches Krebsregister: Schilddrüse (C73) Krebsinzidenz (Neuerkrankungen pro Jahr), Österreich ab 1983 (pdf) http://www.statistik.at/web_de/statistiken/menschen_und_gesellschaft/gesundheit/krebserkrankungen/schilddruese/index.html, Accessed August 24, 2018

[2] Sherman SI. Thyroid carcinoma. Lancet 2003; 31: 501-511

[3] Goldsmith S]. Radioactive iodine therapy of differentiated thyroid carcinoma: Redesigning the paradigm. Mol Imaging Radionucl Ther 2016; 26: (Suppl 1) 74-79

[4] Durante C, Costante G, Filetti S. Differentiated thyroid carcinoma: Defining new paradigms for postoperative management. Endocr Relat Cancer 2013; 20: 141-154

[5] Caetano R, Bastos CR, de Oliveira IA et al. Accuracy of positron emission tomography and positron emission tomography-CT in the detection of differentiated thyroid cancer recurrence with negative (131) I whole-body scan results: A meta-analysis. Head Neck 2016; 38 : 316-327

[6] Palaniswamy SS, Subramanyam P. Diagnostic utility of PET/CT in thyroid malignancies: an update. Ann Nucl Med 2014; 28: 241-247

[7] Haugen BR, Alexander EK, Bible KC et al. 2015 American Thyroid Association Management Guidelines for Adult Patients with Thyroid Nodules an Differentiated Thyroid Cancer: The American Thyroid Association Guidelines Task Force on Thyroid Nodules and Differentiated Thyroid Cancer. Thyroid 2016; 26: 1-133

[8] Wiebel JL, Esfandiari NH, Papaleontiou M et al. Evaluating positron emission tomography use in differentiated thyroid cancer. Thyroid 2015; 25: 1026-1032

[9] Schlumberger M, Sherman SI. Approach to the patient with advanced differentiated thyroid cancer. Eur J Endocrinol 2012; 166: 5-11

[10] Schlumberger M, Brose M, Elisei R, Leboulleux S, Luster M, Pitoia F, Pacini F. Definition and management of radioactive iodine-refractory differentiated thyroid cancer. Lancet Diabetes Endocrinol 2014; 2: 356-358

[11] Baudin E, Schlumberger M. New therapeutic approaches for metastatic thyroid carcinoma. Lancet Oncol 2007; 8: 148-156 
[12] Deandreis D, Al Ghuzlan A, Leboulleux S, Lacroix L, Garsi JP, Talbot M, Lumbroso J, Baudin E, Caillou B, Bidart JM, Schlumberger M. Do histological, immunohistochemical, and metabolic (radioiodine and fluorodeoxyglucose uptakes) patterns of metastatic thyroid cancer correlate with patient outcome? Endocr Relat Cancer 2011; 18 : 159-169

[13] Robbins RJ, Wan Q, Grewal RK, Reibke R, Gonen M, Strauss HW, Tuttle RM, Drucker W, Larson SM. Real-time prognosis for metastatic thyroid carcinoma based on 2-[18F]fluoro-2-deoxy-D-glucose-positron emission tomography scanning. J Clin Endocrinol Metab 2006; 91: 498-505

[14] Leboulleux S, Schroeder PR, Busaidy NL, Auperin A, Corone C, Jacene HA, Ewertz ME, Bournaud C, Wahl RL, Sherman SI, Ladenson PW, Schlumberger M. Assessment of the incremental value of recombinant thyrotropin stimulation before 2-[18F]-fluoro-2-deoxy-D-glucose positron emission tomography/computed tomography imaging to localize residual differentiated thyroid cancer. J Clin Endocrinol Metab 2009; 94: 1310-1316

[15] Leboulleux S, Schroeder PR, Schlumberger M, Ladenson PW. The role of PET in follow-up of patients treated for differentiated epithelial thyroid cancers. Nat Clin Pract Endocrinol Metab 2007; 3: 112-121

[16] Trybek T, Kowalska A, Lesiak J, Mlynarczyk J. The role of 18F-Fluorodeoxyglucose positron emission tomography in patients with suspected recurrence or metastatic differentiated thyroid carcinoma with elevated serum thyreoglobulin and negative I-131 whole body scan. Nucl Med Rev Cent East Eur 2014; 17: 87-93

[17] Na S], Yoo leR OJH, Lin C, Lin Q, Kim SH, Chung SK. Diagnostic accuracy of (18)F-fluorodeoxyglucose positron emission tomography/ computed tomography in differentiated thyroid cancer patients with elevated thyroglobulin and negative (131)I whole body scan: Evaluation by thyroglobulin level. Ann Nucl Med 2012; 26: 26-34

[18] Treglia G, Annunziata S, Muoio B, Salvatori M, Ceriani L, Giovanella L. The role of fluorine-18-fluorodeoxyglucose positron emission tomography in aggressive histological subtypes of thyroid cancer: an overview. Int J Endocrinol 2013; 856189

[19] Rosenbaum-Krumme S], Görges R, Bokisch A, Binse I. 18F-FDG-PET/CT changes therapy management in high-risk DCT after first radioiodine therapy. Eur J Nucl Med Mol Imaging 2012; 39: 1373-1380

[20] Kogai T, Taki K, Brent GA. Enhancement of sodium/iodide symporter expression in thyroid and breast cancer. Endocr Relat Cancer 2006; 13 : 797-826

[21] Dohán O, Baloch Z, Bánrévi Z, Livolsi V, Carrasco N. Predominant intracellular overexpression of $\mathrm{Na}+/ \mathrm{I}-$ symporter (NIS) in a large sampling of thyroid cancer cases. J Clin Endocrinol Metab 2001; 86: 2697-2700

[22] Amit M, Na'ara S, Francis D, Matanis W, Zolotov S, Eisenhaber B, Eisenhaber F, Weiler Sagie M, Malkin L, Billan S, Charas T, Gil Z. Post-translational regulation of radioactive iodine therapy response in papillary thyroid carcinoma. J Natl Cancer Inst 2017; 109. doi: 10.1093/jnci/djx092
[23] Mishra A, Pal L, Mishra SK. Distribution of $\mathrm{Na}+$ /I- symporter in thyroid cancers in an iodine-deficient population: an immunohistochemical study. World J Surg 2007; 31: 1737-1742

[24] Castro M, Bergert ER, Goellner JR, Hay ID, Morris JC. Immunohistochemical analysis of sodium iodide symporter expression in metastatic differentiated thyroid cancer; correlation with radioiodine uptake. J Clin Endocrinol Metab 2001; 86: 5627-5632

[25] Lazar V, Bidart J-M, Caillou B, Mahé C, Lacroix L, Filetti S, Schlumberger $M$. Expression of the of $\mathrm{Na}+/$ I- symporter gene in human thyroid tumors: a comparison study with other thyroid-specific genes. J Clin Endocrinol Metab 1999; 84: 3228-3234

[26] Nascimento C, Borget I, Al Ghuzlan A, Deandreis D, Hartl D, Lumbroso J, Berdelou A, Lepoutre-Lussey C, Mirghani H, Baudin E, Schlumberger M, Leboulleux S. Postoperative fluorine-18-fluorodeoxyglucose positron emission tomography/computed tomography: An important imaging modality in patients with aggressive histology of differentiated thyroid cancer. Thyroid 2015; 25: 437-444

[27] Rivera M, Ghossein RA, Schoder H, Gomez D, Larson SM, Tuttle RM. Histopathologic characterization of radioactive iodine-refractory fluorodeoxyglucose-positron emission tomography-positive thyroid carcinoma. Cancer 2008; 113: 48-56

[28] Alzahrani AS, Abouzied ME, Salam SA, Mohamed G, Rifai A, Al Sugair A, Amin T. The role of $\mathrm{F}$-18-fluorodeoxyglucose positron emission tomography in the postoperative evaluation of differentiated thyroid cancer. Eur J Endocrinol 2008; 158: 683-689

[29] Durante C, Haddy N, Baudin E, Leboulleux S, Hartl D, Travagli JP, Caillou B, Ricard M, Lumbroso JD, De Vathaire F, Schlumberger M. Long-term outcome of 444 patients with distant metastases from papillary and follicular thyroid carcinoma: benefits and limits of radioiodine therapy. J Clin Endocrinol Metab 2006; 91: 2892-2899

[30] Agate L, Bianchi F, Giorgetti A, Sbragia P, Bottici V, Brozzi F, Santini P, Molinaro E, Vitti P, Elisei R, Ceccarelli C. Detection of metastases from differentiated thyroid cancer by different imaging techniques (neck ultrasound, computed tomography and [18F]-FDG positron emission tomography) in patients with negative post-therapeutic 131-I whole-body scan and detectable serum thyreoglobulin levels. J Endocrinol Invest 2014; 37: 967-972

[31] Mirallié E, Guillan T, Bridji B, Resche I, Rousseau C, Ansquer C, Bodet-Milin C, Curtet C, Carnaille B, Murat A, Charbonnel B, Kraeber-Bodéré $F$. Therapeutic impact of 18FDG-PET/CT in the management of iodine-negative recurrence of differentiated thyroid carcinoma. Surgery 2007; 142: 952-958

[32] Brose MS, Nutting CM, Sherman SI, Shong YK, Smit JW, Reike G, Chung J, Kalmus J, Kappeler C, Schlumberger M. Rationale and design of decision: a double-blind, randomized, placebo-controlled phase III trial evaluating the efficacy and safety of sorafenib in patients with locally advanced or metastatic radioactive iodine (RAl)-refractory, differentiated thyroid cancer. BMC Cancer 2011; 11: 349

[33] Rendl G, Rodrigues M, Schweighofer-Zwink G, Hutter ], Hittmair A, Zellinger B, Hauser-Kronberger C, Pirich C. Clinicopathological characteristics of thyroid cancer in the federal state of Salzburg. Wien Klin Wochenschr 2017; 129: 540-544 